\title{
The Inventive Concept in Alice Corp. v. CLS Bank Int'l
}

\author{
Dan L. Burk
}

Published online: 25 November 2014

(C) Max Planck Institute for Innovation and Competition, Munich 2014

The recent decision of the United States Supreme Court in Alice Corp. v. CLS Bank ${ }^{1}$ is the latest and perhaps concluding opinion in a line of cases stretching back into the 1970s, attempting to define the parameters of patentable subject matter. The majority of these cases address process or method patents; nearly all of these cases involve computer software. ${ }^{2}$ But in its Alice Corp. opinion, the Supreme Court offers in the context of American patent law a construction of patentable subject matter that, on careful review, may seem surprisingly familiar to scholars and practitioners versed in European patent law.

The explicit categories of patentable subject matter set forth in Sec. 101 of the American patent statute include processes, machines, articles of manufacture, and compositions of matter. ${ }^{3}$ The Supreme Court has interpreted this list broadly, to include "anything under the sun" made by humans, ${ }^{4}$ and this broad reading includes categories such as business methods that have been seen as problematic in other jurisdictions. ${ }^{5}$ But this reading also implies that subject matter not made by humans, such as natural products or natural principles, is excluded from patent eligibility, and the Court has additionally read the section as excluding certain other inchoate subject matter, such as abstract ideas or mental processes.

\footnotetext{
1134 S.Ct. 2347 (2014). See this issue of IIC at doi:10.1007/s40319-014-0274-z.

2 See Dan L. Burk, "The Curious Incident of the Supreme Court in Myriad Genetics", 90 Notre Dame L. Rev. (forthcoming 2014).

335 U.S.C. $\$ 101$ (2012).

4 Diamond v. Chakrabarty, 447 U.S. 303, 309 (1980).

5 Bilski v. Kappos, 130 S.Ct. 3218 (2010).
}

D. L. Burk $(\bowtie)$

Chancellor's Professor of Law

University of California, Irvine, USA

e-mail: dburk@uci.edu 
The claims in Alice Corp. entailed a computer implemented method for resolving financial transactions by means of a third-party intermediary. The patent included process claims, systems claims drawn to implementation in an digital computer, and media claims drawn to devices inscribed with software. All these were alleged to entail unpatentable abstractions. The Supreme Court decided the question of patent eligibility by applying a two-step test derived from its earlier opinion on diagnostic methods in Mayo v. Prometheus. ${ }^{6}$ As articulated in the Alice Corp. opinion, this test first assesses whether the claims of a patent are directed to a prohibited category such as a "law of nature" or an "abstract idea." If so, then the second step considers whether the claims entail an "inventive concept" that produces something more than an attempt to claim the prohibited subject matter.

The method claims in Alice Corp. failed the test: the Court first determined that they were drawn to the abstract idea of a third-party intermediary in financial transactions. Turning to the second step, the Court determined that the abstract idea was implemented in a generic computer system, and that such a routine or commonplace implementation lacked an "inventive concept." Given that the method claims failed the test, the Court held that the system and media claims failed as well; they were themselves the routine embodiment of the ineligible abstract idea.

Perhaps the most striking feature of the opinion is its focus on the requirement for an "inventive concept." This choice of terminology is perhaps unfortunate, as it closely resembles the terminology of "inventive step" that is used in much of the world to designate the requirement for a patentable invention to be a significant advance over the prior art. Typically the "inventive step" requirement, which is found in many patent systems, including as Art. 52 of the European Patent Convention, ${ }^{7}$ is considered equivalent to the "non-obviousness" requirement found in Sec. 103 of the American patent statute, rather than equivalent to any U.S. subject matter provision.

At the same time, the potentially confusing choice of terminology may ultimately prove instructive. The components of the Alice Corp. test bear comparison to reasoning from the European Patent Office that grapples with essentially the same problem. Article 52 of the European Patent Convention articulates not only the requirement of an "inventive step" but also explicitly lists categories of prohibited subject matter, including categories similar to those formulated in the common law jurisprudence of the United States Supreme Court. ${ }^{8}$ Specifically, Art. 52 excludes discoveries, scientific theories, and mathematical methods, as well as mental acts, business methods, and computer programs "as such." 9

The EPO has struggled for several decades to determine the meaning of the "as such" caveat in the EPC provision. At different times the EPO has deployed different tests, looking sometimes for a "technical contribution" or sometimes for a

\footnotetext{
6132 S.Ct. 1289 (2012).

7 Convention on the Grant of European Patents, Art. 52, Oct. 5, 1973, 1065 U.N.T.S. 199 [hereinafter EPC].

8 Id. at Art. 52(2).

9 Id.
} 
"technical effect" as the hallmark of patentable subject matter. ${ }^{10}$ After a long struggle with the definition of technical subject matter, the EPO appears to have settled on what has been called the "any apparatus" approach; that is, determining that so long as the claims of a patent recite some apparatus, the claims meet the Art. 52 requirements, and probably method claims involving the apparatus do, too. Much like the American subject matter jurisprudence, the EPO decisions such as Hitachi ${ }^{11}$ and Pension Benefits ${ }^{12}$ in which this subject matter rationale was articulated, involve computer implementation of business methods.

Significantly, however, each of these EPO decisions, after conceding that such apparatus-based claims escape Art. 52's subject matter prohibitions, then deny the patent application for lack of an inventive step. The applicants implemented the respective business methods in generic digital processors, which was sufficiently technical for subject matter purposes, but was also, as Americans would say, obvious. Of course, under U.S. law, such a resolution of patentability would constitute impermissible "hindsight reconstruction," that is, judging the obviousness of claims by assuming prior knowledge of the method that is part of the claims. Such assumptions are forbidden in U.S. law by the injunction of the American statute to judge obviousness of the invention as a whole in light of the prior art at the time an application is filed. ${ }^{13}$

And yet the United States Supreme Court has now reached a result very similar to that of the EPO without employing forbidden hindsight reconstruction. The Alice Corp. opinion avoids that problem by incorporating something like an obviousness test, the "inventive concept" test, into the second step of the Sec. 101 subject matter determination. Section 101 states no temporal prohibition such as that in the Sec. 103 obviousness provisions. And at the same time, step one of the Alice Corp. test impels patentees toward narrower, specific apparatus claims, effectively paralleling the "any apparatus" subject matter approach in the EPO. Thus, it seems that with this latest Supreme Court opinion, the subject matter jurisprudence on both sides of the Atlantic may be converging on similar standards.

\footnotetext{
10 See Rosa Marie Ballardini, "Software Patents in Europe: The Technical Requirement Dilemma”, 3 J. Intellectual Prop. L. \& Prac. 563, 565-66 (2008).

11 T 0258/03 Auction Method/Hitachi [2004] OJEPO 575.

12 T 0931/195 Controlling Pension Benefit Systems/PBS Partnership [2001] OJEPO 441.

1335 U.S.C. § 103 (2012).
} 